Article

\title{
Individual Gas Molecules Detection Using Zinc Oxide-Graphene Hybrid Nanosensor: A DFT Study
}

\author{
Ingrid Torres ${ }^{1}$, Sadegh Mehdi Aghaei ${ }^{1, *}{ }^{\mathbb{C}}$, Amin Rabiei Baboukani ${ }^{2}{ }^{(\mathbb{D}}$, Chunlei Wang ${ }^{2}$ and \\ Shekhar Bhansali ${ }^{1}$ \\ 1 Department of Electrical and Computer Engineering, Florida International University, \\ Miami, FL 33174, USA; itorr001@fiu.edu (I.T.); sbhansa@fiu.edu (S.B.) \\ 2 Department of Mechanical and Materials Engineering, Florida International University, \\ Miami, FL 33174, USA; arabi009@fiu.edu (A.R.B.); wangc@fiu.edu (C.W.) \\ * Correspondence: smehd002@fiu.edu; Tel.: +1-305-332-8084
}

Received: 26 June 2018; Accepted: 4 August 2018; Published: 9 August 2018

\begin{abstract}
Surface modification is a reliable method to enhance the sensing properties of pristine graphene by increasing active sites on its surface. Herein, we investigate the interactions of the gas molecules such as $\mathrm{NH}_{3}, \mathrm{NO}, \mathrm{NO}_{2}, \mathrm{H}_{2} \mathrm{O}$, and $\mathrm{H}_{2} \mathrm{~S}$ with a zinc oxide ( $\mathrm{ZnO}$ )-graphene hybrid nanostructure. Using first-principles density functional theory (DFT), the effects of gas adsorption on the electronic and transport properties of the sensor are examined. The computations show that the sensitivity of the pristine graphene to the above gas molecules is considerably improved after hybridization with zinc oxide. The sensor shows low sensitivity to the $\mathrm{NH}_{3}$ and $\mathrm{H}_{2} \mathrm{O}$ because of the hydrogen-bonding interactions between the gas molecules and the sensor. Owing to observable alterations in the conductance, large charge transfer, and high adsorption energy; the sensor possesses extraordinary potential for $\mathrm{NO}$ and $\mathrm{NO}_{2}$ detection. Interestingly, the $\mathrm{H}_{2} \mathrm{~S}$ gas is totally dissociated through the adsorption process, and a large number of electrons are transferred from the molecule to the sensor, resulting in a substantial change in the conductance of the sensor. As a result, the $\mathrm{ZnO}$-graphene nanosensor might be an auspicious catalyst for $\mathrm{H}_{2} \mathrm{~S}$ dissociation. Our findings open new doors for environment and energy research applications at the nanoscale.
\end{abstract}

Keywords: graphene; zinc oxide; $\mathrm{ZnO}$; sensor; $\mathrm{NH}_{3} ; \mathrm{NO} ; \mathrm{NO}_{2} ; \mathrm{H}_{2} \mathrm{~S}$; adsorption; density functional theory (DFT)

\section{Introduction}

There are presently great efforts being made in developing novel gas sensors centered around new nanomaterials for the detection of toxic gases since they offer higher sensitivity, selectivity, and reliability; as well as immediate response and recovery at low cost. One of the most significant advantages that nanostructure-based sensors have over conventional microsensors is the high surface-to-volume ratio. This is a crucial parameter since it defines the sensitivity of the gas sensors. Moreover, the nanostructured materials provide a greater detection area leading to better adsorption of gas species and an increase in sensing abilities.

Graphene, the first discovered two-dimensional (2D) material, has become a promising material for different types of applications [1,2]. Graphene's amazing properties have attracted considerable interest in the area of gas sensing since they enable the improvement of miniaturized sensors at low cost and power consumption [3-5]. Consequently, graphene has been extensively studied theoretically [6-14] and experimentally [15-20]. On the downside, because of the weak interactions between $\pi$ electrons of graphene's surface and the gas molecules, pristine graphene has shown limitations for the recognition of individual gas particles [9,10], exhibiting low sensitivity to common 
gases such as $\mathrm{CO}, \mathrm{CO}_{2}, \mathrm{CH}_{4}, \mathrm{~N}_{2}, \mathrm{NO}_{2}, \mathrm{NH}_{3}, \mathrm{H}_{2}$, and $\mathrm{H}_{2} \mathrm{O}$ [6-8]. Therefore, physical or chemical modification of graphene's surface has been considered to boost its performance. Hydrogen plasma [21], reduction reagents [22], and electron beam irradiation [23] are the physical methods that have been applied to modify the surface of the graphene by reducing the graphene oxide (GO). Besides the physical modification, chemical methods such as functionalization, impurity atom doping, and defects have been reported to successfully alter the electrical and magnetic properties of nanomaterials [24-32]. Techniques, where dopants or defects are introduced, have shown an improvement in the sensitivity of the graphene-based gas sensors [7,8,11-14,28-30,33]. Zhang et al. showed small gas molecules such as $\mathrm{NO}_{2}, \mathrm{CO}, \mathrm{NO}$, and $\mathrm{NH}_{3}$ display strong reactions with B-doped, $\mathrm{N}$-doped, and defective graphene [7]. Additionally, when graphene is doped with $\mathrm{B}, \mathrm{N}$, and $\mathrm{Si}$, it displayed boosted interactions with other common gases like $\mathrm{N}_{2}, \mathrm{SO}_{2}, \mathrm{CO}_{2}, \mathrm{O}_{2}, \mathrm{H}_{2}$, and $\mathrm{H}_{2} \mathrm{O}$ compared to pristine graphene [8]. Doped graphene with transition metals ( $\mathrm{Fe}, \mathrm{Co}, \mathrm{Ni}, \mathrm{Ru}, \mathrm{Rh}, \mathrm{Pd}, \mathrm{Os}$, $\mathrm{Ir}$, and $\mathrm{Pt}$ ) has also been demonstrated to have high sensitivity to $\mathrm{O}_{2}$ adsorption [12]. Borisova et al. noticed that when defects are induced on graphene, it improved the interactions of $\mathrm{H}_{2} \mathrm{~S}$ with $\mathrm{C}$ atoms, showing much better response in comparison with pristine graphene [13]. Density functional theory (DFT) calculation on Eu-decorated single- and double-sided graphene sheets exhibited that each Eu could firmly bound to six $\mathrm{H}_{2}$ molecules [14]. Recently, the sensitivity of other 2D nanomaterials such as $\mathrm{MoS}_{2}$ [34-36], phosphorene [37,38], hexagonal boron carbide (BC 3 ) [39,40], $\mathrm{WS}_{2}$ [41,42], silicene [43-45], and germanene [46] to several gases have been inspected.

Metal oxides like $\mathrm{SnO}_{2}, \mathrm{WO}_{3}$, etc. have been commonly integrated on gas sensors to improve their performance, specifically their sensitivity and selectivity [47-52]. However, these types of sensors have a significant constraint since they need to operate at high temperatures, between $200-600{ }^{\circ} \mathrm{C}$, limiting their application and integration as well as presenting energy consumption issues and risks of gas explosion. Recently, metal oxide gas sensors (including $\mathrm{Cu}_{2} \mathrm{O}, \mathrm{In}_{2} \mathrm{O}_{3}, \mathrm{Co}_{3} \mathrm{O}_{4}$ ) have been hybridized with graphene to boost their ability of gas detection at room temperature [53-64].

Zinc oxide $(\mathrm{ZnO})$ is a rising and significant semiconductor due to its large direct band gap of $0.37 \mathrm{eV}$ and large exciton binding energy of $60 \mathrm{mV}$. $\mathrm{ZnO}$ nanoparticles are very popular to use in graphene hybrid systems because it is easy to control their size, morphology, and material properties. We have recently reported decoration of graphene with $\mathrm{Zn}_{12} \mathrm{O}_{12}$ nanoclusters to open a band gap of $14.5 \mathrm{meV}$ around the Fermi level at K-point [65]. Graphene decorated with $\mathrm{ZnO}$ nanoparticles has been proven to heighten the sensitivity towards common toxic gases like $\mathrm{CO}, \mathrm{NH}_{3}, \mathrm{NO}$ [55], methane [66], $\mathrm{NO}_{2}[67,68]$, formaldehyde [69,70], $\mathrm{H}_{2}$ [63], and also to humidity [71].

The objective of this study is employing DFT in order to analyze the electronic and transport properties of the zinc oxide-graphene hybrid nanosensor when in close proximity to the gas molecules such as $\mathrm{NH}_{3}$, $\mathrm{NO}, \mathrm{NO}_{2}, \mathrm{H}_{2} \mathrm{O}$, and $\mathrm{H}_{2} \mathrm{~S}$. Variations in the electronic transport properties of the $\mathrm{ZnO}$-graphene sensors are correlated with the sensitivity capability of the device. Our results reveal the promising future of $\mathrm{ZnO}-$ graphene hybrid nanostructure in the development of ultra-high sensitive gas sensors.

\section{Computational Methods}

This paper presents first-principles calculations based on DFT in combination with the non-equilibrium Green's Function (NEGF) method performed in the Atomistix ToolKit (ATK) software package [72-74]. The Perdew, Burke, and Ernzerh (PBE) approach of generalized gradient approximation (GGA) is used for the exchange-correlation function. To expand the electron wave function, a double- $\zeta$ polarized basis set is employed. The Grimme van der Waals (vdW) correction (PBE-D2) [75] is utilized in order to take into account the long-range $\mathrm{vdW}$ interactions in the adsorption systems [76]. The electronic temperature is kept constant at $300 \mathrm{~K}$, and the plane wave mesh cut-off energy is set to 150 Rydberg.

To mimic a free-standing graphene sheet, we consider a periodic $(3 \times 10)$ supercell of graphene in $y$ and $z$ dimensions. To avoid any image interactions, a vacuum spacing of $15 \AA$ is imposed on the plane in the $x$-direction in which the sheet is not periodic. By employing the conjugate gradient method, the 
supercell is allowed to optimize fully until all the final atomic forces are less than $0.01 \mathrm{eV} / \AA$. The first Brillouin zones are sampled using $1 \times 21 \times 11 \mathrm{k}$-points in the $x, y$, and $z$ directions, respectively. In the next step, zinc oxide is placed in the center of the supercell in the vicinity of the $C$ atoms, and then the whole system is optimized again. For the calculations, we increase the k-points to $1 \times 121 \times 111$ in the $x, y$, and $z$ directions, respectively. The adsorption energy gives us a quantitative explanation of the interaction strength between adsorbent and adsorbate. The adsorption energy of zinc oxide onto the graphene sheet is computed from:

$$
E_{a d(\mathrm{ZnO})}=E_{Z n O-\text { Graphene }}-E_{\text {Graphene }}-E_{Z n O}
$$

Here, $E_{Z n O-G r a p h e n e}, E_{\text {Graphene, }}$ and $E_{Z n O}$ are the total energies of the $\mathrm{ZnO}$-graphene system, pristine graphene sheet, and the isolated $\mathrm{ZnO}$, respectively. In the last step, the gas molecules including $\mathrm{NH}_{3}, \mathrm{NO}, \mathrm{NO}_{2}, \mathrm{H}_{2} \mathrm{O}$, and $\mathrm{H}_{2} \mathrm{~S}$ are added to the system by placing them in the vicinity of the $\mathrm{ZnO}$. The gas molecule- $\mathrm{ZnO}-$ graphene complexes are completely relaxed. The adsorption energies of the gas molecules on the $\mathrm{ZnO}-$ graphene system are obtained by:

$$
E_{\text {ad }(\text { Molecule })}=E_{\text {Molecule }-Z n O-G r a p h e n e}-E_{Z n O-\text { Graphene }}-E_{\text {Molecule }}
$$

where $E_{\text {Molecule-ZnO-Graphene }}$ is the total energy of the molecule-ZnO-graphene compound and $E_{\text {Molecule }}$ is the energy of an isolated gas molecule. Mulliken population analysis is engaged to study the charge transfer between the graphene and $\mathrm{ZnO}$ and between the gas molecules and the $\mathrm{ZnO}-$ graphene system. To simulate the gas sensing system and analyze its electronic and transport properties, the structure is converted to a two-point probe sensor, as shown in Figure 1. The sensor consists of 120 atoms of $C$ which is functionalized with the zinc oxide. It also includes a scattering region $\left(12.8 \times 24.6 \AA^{2}\right)$ and $4.92 \AA$ electrodes on each side. It should be noted that the left and right electrodes (the black boxes) are semi-infinite until cells and are repeated along the $z$-axis. Moreover, the scattering region is periodic along the $y$-axis. We describe the quantum conductance of the system via the transmission coefficient at the Fermi level:

$$
C(E)=G_{0} T(E)
$$

where $G_{0}=2 e^{2} / h$ is the quantum conductance constant ( $e$ is the electron charge and $h$ is Planck's constant). The transmission is calculated along the $z$-direction. Moreover, transmission coefficients at energy $E$ can be expressed based on the retarded Green's function $G^{\dagger}(E)$ and the advanced Green's functions $G(E)$ of the scattering region.

$$
T(E)=G(E) \Gamma^{L}(E) G^{\dagger}(E) \Gamma^{R}(E)
$$

Here, $\Gamma^{L(R)}(E)$ is the coupling function of the left (right) electrode which is:

$$
\Gamma^{L(R)}=\frac{1}{i}\left(\sum^{L(R)}-\left(\sum^{L(R)}\right)^{\dagger}\right)
$$

where $\sum^{L(R)}$ is the electrode self-energy of the left (right) electrode. 


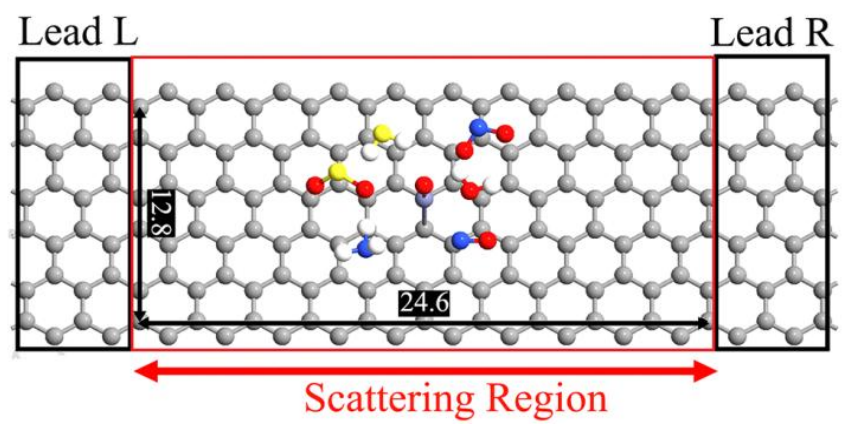

Figure 1. Schematic illustration of zinc oxide $(\mathrm{ZnO})$-graphene hybrid gas sensor with two leads (black boxes). The gray, purple, red, blue, yellow, and white balls represent $\mathrm{C}, \mathrm{Zn}, \mathrm{O}, \mathrm{N}, \mathrm{S}$, and $\mathrm{H}$ atoms, respectively. The length and the width of the scattering region (red box) of the sensor (in unit of $\AA$ ) are also provided.

\section{Results and Discussion}

We first optimize the $\mathrm{ZnO}$-graphene hybrid nanostructure in order to obtain the most energetically stable geometry of the sensor. $\mathrm{ZnO}$ can adhere to the graphene at different positions including the atom site (above $\mathrm{C}$ atom), bridge site (above $\mathrm{C}-\mathrm{C}$ bond), and hollow site (center of $\mathrm{C}-\mathrm{C}$ hexagons). Additionally, concerning the surface of the graphene sheet, a $\mathrm{ZnO}$ can be aligned parallel or upright at these specific positions. The most stable configuration is found by full relaxation of all the possible structures and comparing their final adsorption energies. The most energetically favorable adsorption configuration, which is the arrangement with the minimum adsorption energy, is shown in Figure 2a. Our DFT calculations show that $\mathrm{ZnO}$ prefers to place itself perpendicular with respect to the graphene plane, while the $\mathrm{Zn}$ atom heading to the $\mathrm{C}$ atoms and the $\mathrm{O}$ atom way around. The $\mathrm{Zn}$ atom is located above the middle of the $C_{1}-C_{2}$ bond and is bonded to $C$ atoms on the graphene sheet to form a $\mathrm{Zn}-\mathrm{C}_{1}-\mathrm{C}_{2}$ triangle with $\mathrm{Zn}-\mathrm{C}_{1}, \mathrm{Zn}-\mathrm{C}_{2}$, and $\mathrm{C}_{1}-\mathrm{C}_{2}$ side lengths of $2.24,2.20$, and $1.44 \AA$, respectively. The $\mathrm{C}_{1}-\mathrm{Zn}-\mathrm{C}_{2}$ angle is $37.95^{\circ}$. The $\mathrm{Zn}-\mathrm{O}$ bond length in isolated $\mathrm{ZnO}(2.00 \AA)$ is reduced to $1.70 \AA$ after interaction with $\mathrm{C}$ atoms of the graphene sheet. For $\mathrm{ZnO}$-graphene nanostructure, an adsorption energy of $-0.68 \mathrm{eV}$ is obtained that could be indicative of moderate chemisorption. This chemisorption accompanies with an electron transfer of $0.105 e$ from $\mathrm{ZnO}$ to graphene. These findings can be confirmed by comparing the band structures of the pristine graphene sheet and the $\mathrm{ZnO}$-graphene hybrid nanostructure, as depicted in Figure $2 b$. The dashed green curves show the reference results for a pristine graphene sheet. As we know, graphene has no band gap. This means the valence and conduction bands touch at the Dirac points. Upon exposure to zinc oxide, the induced electrons shifted down the Dirac point of the graphene towards negative energies and moved the Fermi level to the conduction band, as shown in Figure $2 \mathrm{~b}$ in solid black curves. This suggests that the n-type doping effect of graphene has taken place. The Dirac point of the graphene is distorted after interaction with the $\mathrm{ZnO}$ due to breakage of bond symmetry in graphene. Interestingly, a gap of $26 \mathrm{meV}$ is observable between the bands $c$ (shifted conduction band) and $v$ (shifted valence band) of the $\mathrm{ZnO}$-graphene hybrid.

Next, the adsorption mechanisms of the $\mathrm{NH}_{3}, \mathrm{NO}, \mathrm{NO}_{2}, \mathrm{H}_{2} \mathrm{~S}$, and $\mathrm{H}_{2} \mathrm{O}$ gas molecules onto a graphene- $\mathrm{ZnO}$ nanostructure sheet are addressed. In the first step, each gas molecule is placed at a distance of $2 \AA$ above the $\mathrm{O}$ atom of the $\mathrm{ZnO}$-graphene nanostructure. Some initial configurations are considered. The gas molecules can be aligned in parallel or perpendicular concerning the surface of the $\mathrm{ZnO}-$ graphene nanostructure. Further, the $\mathrm{N}$ atom of $\mathrm{NO}$ with a diatomic molecular structure can point up or down to the $\mathrm{ZnO}$-graphene nanostructure. For the triatomic molecules $\left(\mathrm{NO}_{2}, \mathrm{H}_{2} \mathrm{O}\right.$, and $\left.\mathrm{H}_{2} \mathrm{~S}\right)$ and tetratomic molecule $\left(\mathrm{NH}_{3}\right)$, two orientations are examined. In the first orientation, the $\mathrm{N}$ atom (in $\mathrm{NH}_{3}$ and $\mathrm{NO}_{2}$ ), $\mathrm{O}$ atom (in $\mathrm{H}_{2} \mathrm{O}$ ), and $\mathrm{S}$ atom (in $\mathrm{H}_{2} \mathrm{~S}$ ), point to the $\mathrm{O}$ atom of the $\mathrm{ZnO}$-graphene nanostructure, while, in the second one, the $\mathrm{O}$ atom (in $\mathrm{NO}_{2}$ ) and $\mathrm{H}$ atom (in $\mathrm{NH}_{3}, \mathrm{H}_{2} \mathrm{O}$, and $\mathrm{H}_{2} \mathrm{~S}$ ) point down to the surface of the sensor. In the second step, all the input structures are allowed to fully 
optimize. Once improved, the structural stability is studied regarding the adsorption energy. The most stable configurations which have the most negative adsorption energies are chosen for further analysis and are depicted in Figure 3. The conventional sensing mechanism is that charge transfer between the adsorbed gas molecules and the surface of the 2D nanomaterials is expected to affect the conductivity of the system upon exposure to the target gas molecules, while the chemical structure of the sensing layer is preserved. The adsorption energies of the gas molecules on the $\mathrm{ZnO}$-graphene nanostructure, the minimum binding distances, and the net charge transfer on molecules using Mulliken population analysis are summarized in Table 1.

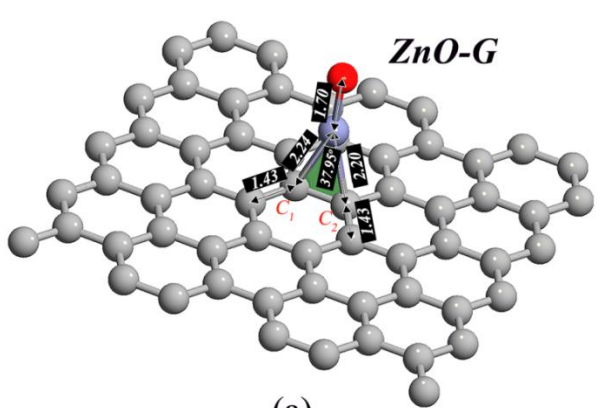

(a)

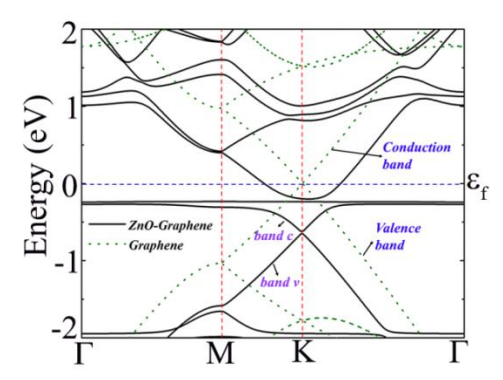

(b)

Figure 2. (a) Relaxed configuration of the $\mathrm{ZnO}$ adsorbed onto a graphene sheet. The gray, purple, and red balls signify $C, Z n$, and $O$ atoms, respectively. The green area highlights the $C_{1}-Z n-C_{2}$ angle. The bond lengths and the binding distances between the $\mathrm{ZnO}$ and the graphene sheet (in unit of $\AA$ ) are also given. (b) The band structures of pristine graphene (dashed green curves) and the $\mathrm{ZnO}$-graphene hybrid (solid black curves).

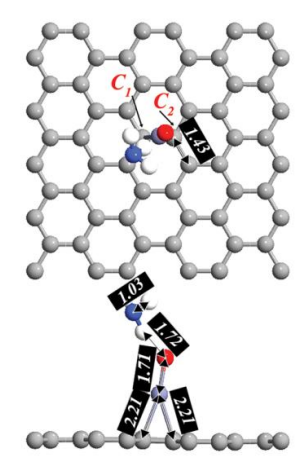

$$
\mathrm{NH}_{3}-\mathrm{ZnO}-\mathrm{G}
$$
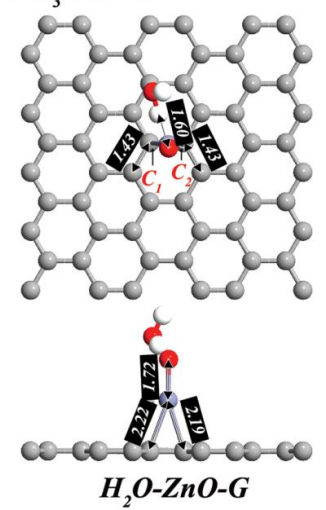
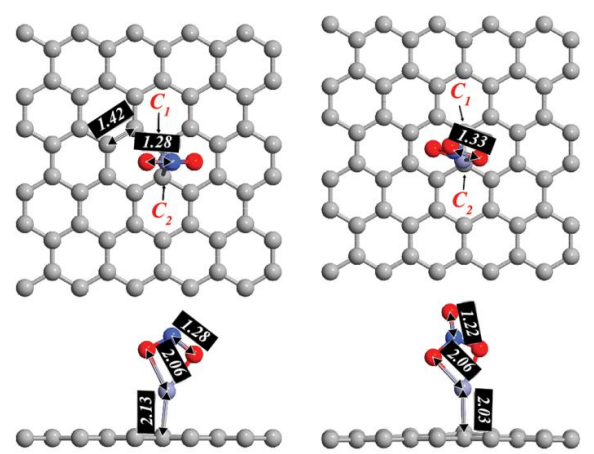

$\mathrm{NO}-\mathrm{ZnO}-\mathrm{G}$
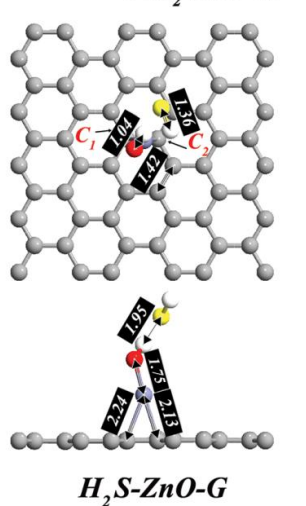

Figure 3. The most stable adsorption configurations (top and side view) for $\mathrm{NH}_{3}, \mathrm{NO}, \mathrm{NO}_{2}, \mathrm{H}_{2} \mathrm{O}$, and $\mathrm{H}_{2} \mathrm{~S}$ on the $\mathrm{ZnO}$-graphene sensor. The gray, purple, red, blue, yellow, and white balls represent $\mathrm{C}, \mathrm{Zn}$, $\mathrm{O}, \mathrm{N}, \mathrm{S}$, and $\mathrm{H}$ atoms, respectively. The bond lengths (in unit of $\AA$ ) and the binding distances between the molecule and the sensor are also provided. 
Table 1. The calculated adsorption energy $\left(E_{a d}\right)$, binding distance $(D)$ which is the shortest atom to atom distance between the molecule and the sensor, the charge transfer $(Q)$, and the evaluated value of the sensitivity of the sensor with respect to each gas molecule $(S)$. The positive value of charge indicates a charge transfer from the molecule to the sensor.

\begin{tabular}{ccccc}
\hline System & $\boldsymbol{E}_{\boldsymbol{a d}}(\mathbf{e V})$ & $\boldsymbol{D}(\mathbf{\mathrm { A }})$ & $\boldsymbol{Q}(\boldsymbol{e})$ & $\boldsymbol{S} \mathbf{( \% )}$ \\
\hline $\mathrm{NH}_{3}-\mathrm{ZnO}-\mathrm{G}$ & -0.55 & 1.72 & +0.056 & 11.8 \\
$\mathrm{NO}-\mathrm{ZnO}-\mathrm{G}$ & -2.21 & 1.28 & +0.155 & 188.2 \\
$\mathrm{NO}_{2}-\mathrm{ZnO}-\mathrm{G}$ & -1.85 & 1.33 & +0.141 & 141.1 \\
$\mathrm{H}_{2} \mathrm{O}-\mathrm{ZnO}-\mathrm{G}$ & -0.32 & 1.60 & +0.031 & 6.4 \\
$\mathrm{H}_{2} \mathrm{~S}-\mathrm{ZnO}-\mathrm{G}$ & -1.01 & 1.04 & +0.121 & 76.47 \\
\hline
\end{tabular}

We first scrutinize the interactions of the $\mathrm{NH}_{3}$ molecule and the $\mathrm{ZnO}-$ graphene compound. As can be seen in Figure 3, $\mathrm{H}$ atom of the $\mathrm{NH}_{3}$ molecule interacts with the $\mathrm{O}$ atom of the $\mathrm{ZnO}$-graphene nanostructure. The interaction distance $\mathrm{H}-\mathrm{O}$ is found to be $1.72 \AA$ which is larger than the sum of the covalent radii of the $\mathrm{H}$ and $\mathrm{O}$ atoms $(0.95 \AA)$ [77]. Furthermore, the adsorption energy is calculated to be $-0.55 \mathrm{eV}$ that is large enough to form a hydrogen bond between the $\mathrm{NH}_{3}$ and the sensor $(\mathrm{H}-\mathrm{O})$. A hydrogen bond is a weak interaction whose strength can be placed between the chemical bond and the vdW force [78]. One can say that the $\mathrm{NH}_{3}$ molecule is only physically adsorbed on the surface while maintaining its molecular form. The $C_{1}-C_{2}$ bond length remains unchanged while both $\mathrm{Zn}-\mathrm{C}_{1}$ and $\mathrm{Zn}-\mathrm{C}_{2}$ bond lengths are slightly altered to $2.21 \AA$. The $\mathrm{C}_{1}-\mathrm{Zn}-\mathrm{C}_{2}$ angle is reduced from $37.95^{\circ}$ to $14.86^{\circ}$. The bond lengths of $\mathrm{N}-\mathrm{H}$ in an isolated $\mathrm{NH}_{3}(1.03 \AA)$ are found to be the same after adsorption onto the $\mathrm{ZnO}$-graphene. These small variations substantiate that the influence of $\mathrm{NH}_{3}$ adsorption onto the sensor is trivial. This observation can be further verified by the low amount of charge $(0.056 e)$ that is transferred from the $\mathrm{NH}_{3}$ to the graphene-based sensor. Excitingly, the calculated adsorption energy for the $\mathrm{NH}_{3}-\mathrm{ZnO}$-graphene complex is greater than that obtained for $\mathrm{NH}_{3}$ adsorption onto pristine graphene $(-0.11 \mathrm{eV})[7]$ and is less than the ammonia adsorption energy on the $\mathrm{ZnO}(10 \overline{1} 0)$ $(-1.32 \mathrm{eV})$ [79], $\mathrm{ZnO}(0001)(-2.21 \mathrm{eV})$ [80], and $\mathrm{ZnO}(6,0)$ single-walled nanotube $(-0.82 \mathrm{eV})$ [81] surfaces, revealing that hybridization of pristine graphene with $\mathrm{ZnO}$ increases its adsorption capability toward $\mathrm{NH}_{3}$ significantly. This is in accordance with the experimental data. It was reported that sensors based on $\mathrm{ZnO}$-decorated graphene oxide sheets can detect $\mathrm{NH}_{3}$ for concentrations as low as $1 \mathrm{ppm}$ at room temperature [55].

Next, the interactions of the $\mathrm{NO}$ and $\mathrm{NO}_{2}$ gas molecules with the $\mathrm{ZnO}$-graphene hybrid are inspected. The relaxed structures are provided in Figure 3. The adsorption energies of $\mathrm{NO}$ and $\mathrm{NO}_{2}$ are -1.21 and $-1.85 \mathrm{eV}$, respectively. One can conclude that there exists a strong chemisorption characteristic between $\mathrm{NO}$ and $\mathrm{NO}_{2}$ gas molecules and the sensor. Upon adsorption of $\mathrm{NO}$ on the $\mathrm{ZnO}$-graphene compound, the $\mathrm{C}_{1}-\mathrm{C}_{2}$ bond length is elongated to $1.45 \AA$, while $\mathrm{Zn}-\mathrm{C}_{1}$ and $\mathrm{Zn}-\mathrm{C}_{2}$ bond lengths are shortened to 2.13 and $2.18 \AA$, respectively. Additionally, the $C_{1}-Z n-C_{2}$ angle is slightly increased to $39.58^{\circ}$. The $\mathrm{N}$ and $\mathrm{O}$ atoms of the $\mathrm{NO}$ interact with $\mathrm{O}$ and $\mathrm{Zn}$ atoms of $\mathrm{ZnO}$, respectively, to form a kite where its four sides can be grouped into two pairs of equal-length sides $(\mathrm{N}-\mathrm{O}$ and $\mathrm{Zn}-\mathrm{O})$ that are adjacent to each other. The length of $\mathrm{N}-\mathrm{O}$ is $1.28 \AA$ and $\mathrm{Zn}-\mathrm{O}$ equals to $2.06 \AA$. The $\mathrm{N}-\mathrm{O}$ bond length is stretched from $1.17 \AA$ in an isolated NO molecule to $1.28 \AA$ in the NO-ZnO-graphene system. The $\mathrm{O}-\mathrm{N}-\mathrm{O}$ and $\mathrm{O}-\mathrm{Zn}-\mathrm{O}$ angles of the kite are $113.10^{\circ}$ and $92.46^{\circ}$, respectively. The interaction of $\mathrm{NO}_{2}$ and $\mathrm{ZnO}-$ graphene bears many similarities to that of the $\mathrm{NO}$ and $\mathrm{ZnO}-$ graphene. In much the same manner, the interaction between the $\mathrm{NO}$ part of the $\mathrm{NO}_{2}$ molecule and $\mathrm{ZnO}$ results in the $\mathrm{Zn}-\mathrm{O}-\mathrm{N}-\mathrm{O}$ kite. In this geometry, the lengths of the $\mathrm{N}-\mathrm{O}$ sides equal to $1.33 \AA$ and the $\mathrm{Zn}-\mathrm{O}$ sides have the length of $2.06 \AA$. The $\mathrm{O}-\mathrm{N}-\mathrm{O}$ and $\mathrm{O}-\mathrm{Zn}-\mathrm{O}$ angles of the kite are $113.92^{\circ}$ and $91.16^{\circ}$, respectively. In comparison with the length of $\mathrm{N}-\mathrm{O}$ bonds in the isolated $\mathrm{NO}_{2}(1.21 \AA)$, the $\mathrm{N}-\mathrm{O}$ bond of the $\mathrm{NO}_{2}$ in the kite gets extended to $1.33 \AA$, while the second $\mathrm{N}-\mathrm{O}$ bond of the molecule remains almost unchanged. It should be added that the $\mathrm{O}-\mathrm{N}-\mathrm{O}$ bond angle of isolated $\mathrm{NO}_{2}$ decreases from $133.06^{\circ}$ to $122.38^{\circ}$ after complexation with $\mathrm{ZnO}-$ graphene compound. Despite the resemblances above between $\mathrm{NO}$ and $\mathrm{NO}_{2}$ 
adsorption on the $\mathrm{ZnO}$-graphene sensor, the $\mathrm{Zn}$ atom is shifted from above the middle of $\mathrm{C}_{1}-\mathrm{C}_{2}$ bond to top of the $C_{2}$ atom, where both $Z n-C_{1}$ and $Z n-C_{2}$ bond lengths are 2.50 and $2.03 \AA$, respectively. Interestingly, after exposure to $\mathrm{NO}_{2}$, the $\mathrm{C}_{1}-\mathrm{C}_{2}$ bond length is stretched to $1.46 \AA$. Additionally, the $\mathrm{C}_{2}$ atom protrudes outwards after $\mathrm{NO}_{2}$ adsorption with a buckling distance of $\sim 0.302 \AA$. These noticeable changes in the structure of the $\mathrm{ZnO}$-graphene sensor are indicative of the chemical adsorption of $\mathrm{NO}$ and $\mathrm{NO}_{2}$ and agree well with the calculated adsorption energies for the gas molecules on the sensor. The obtained adsorption energies for $\mathrm{NO}(-1.21 \mathrm{eV})$ and $\mathrm{NO}_{2}(-1.85 \mathrm{eV})$ on the $\mathrm{ZnO}-$ graphene are considerably higher compared to those reported for $\mathrm{NO}(-0.30 \mathrm{eV})$ and $\mathrm{NO}_{2}(-0.48 \mathrm{eV})$ adsorption onto pristine graphene [7] and those obtained for $\mathrm{NO}(-0.28 \mathrm{eV})$ and $\mathrm{NO}_{2}(-0.36 \mathrm{eV})$ adsorption onto the $\mathrm{ZnO}(10 \overline{10})$ surface [82] and for $\mathrm{NO}(-0.40 \mathrm{eV})$ and $\mathrm{NO}_{2}(-0.31 \mathrm{eV})$ adsorption onto the $\mathrm{ZnO}$ (2110) surface [83]. It should be noted that the gas adsorption does not change the chemical structure of the sensing layer. As mentioned earlier, the sensing mechanism of the gas molecules is due to the charge transfer between the target gas molecules and the sensing layer. A significant amount of charge transfer is observed from $\mathrm{NO}(0.155 e)$ and $\mathrm{NO}_{2}(0.141 e)$ to the sensor. The large electron transfer in these systems can be attributed to the strong chemisorption of the $\mathrm{NO}$ and $\mathrm{NO}_{2}$ gas molecules on the sensor. Such a large charge transfer is expected to induce considerable changes in the conductivity of the system which will be discussed later. The experimental data support our theoretical findings. Singh et al. discovered that $\mathrm{ZnO}$ decorated graphene sheet sensor responses to $5 \mathrm{ppm} \mathrm{NO}$ gas in dry nitrogen at room temperature [55]. Furthermore, Liu et al. reported that the introduction of $\mathrm{ZnO}$ nanoparticles into reduced graphene oxide matrix enhances its sensing performance for $\mathrm{NO}_{2}$ at room temperature [67].

We also evaluate the sensitivity of the $\mathrm{ZnO}$-graphene sensor to the $\mathrm{H}_{2} \mathrm{O}$ and $\mathrm{H}_{2} \mathrm{~S}$ gas molecules. Figure 3 depicts the most stable configuration of the $\mathrm{H}_{2} \mathrm{O}$ and $\mathrm{H}_{2} \mathrm{~S}-\mathrm{ZnO}$-graphene complexes. For $\mathrm{H}_{2} \mathrm{O}$, our computational results indicate that it is weakly physisorbed on the sensor with an adsorption energy of $-0.32 \mathrm{eV}$ which is higher than its adsorption energy on pristine graphene $(-0.027 \mathrm{eV})$ [84] and the pristine $\mathrm{ZnO}(0001)$ surface $(-0.28 \mathrm{eV})$ [85], while it is less than its adsorption energy on the pristine $\mathrm{ZnO}(10 \overline{1} 0)$ surface $(-0.94 \mathrm{eV})$ [86]. Hence, the $\mathrm{ZnO}-$ graphene sensor demonstrates promise to work under humid air. A charge of $0.031 e$ is transferred from the water molecule to the sensor. The minimum distance between the $\mathrm{H}_{2} \mathrm{O}$ and the sensor is $1.60 \AA$ and this occurred between $\mathrm{H}$ of the $\mathrm{H}_{2} \mathrm{O}$ and $\mathrm{O}$ of the $\mathrm{ZnO}$ which is larger than the sum of the covalent radii of the $\mathrm{H}$ and $\mathrm{O}$ atoms $(0.95 \AA)$ [77]. One can conclude that there exists a weak hydrogen-bonding interaction between $\mathrm{H}_{2} \mathrm{O}$ and the sensor. Therefore, the sensor undergoes minor structural changes when is exposed to $\mathrm{H}_{2} \mathrm{O}$ (also known as, humidity). Consequently, $\mathrm{H}_{2} \mathrm{O}$ is only physisorbed on the surface while preserving its molecular form. The $\mathrm{Zn}-\mathrm{C}_{1}$ and $\mathrm{Zn}-\mathrm{C}_{2}$ are slightly reduced to 2.22 and $2.19 \AA$, respectively, while $C_{1}-C_{2}$ is kept unchanged. The $C_{1}-Z n-C_{2}$ angle is increased to $38.22^{\circ}$, and the $\mathrm{Zn}-\mathrm{O}$ bond length is extended to $1.72 \AA$. These small variations in the sensor are in agreement with the results obtained for the adsorption energy and charge transfer, and confirm the weak physisorption of the water molecule by the sensor. The $\mathrm{H}_{2} \mathrm{~S}$ adsorption mechanism on $\mathrm{ZnO}$-graphene is more complicated than the other molecules studied above. The $\mathrm{H}_{2} \mathrm{~S}$ molecule and the sensor experience substantial structural changes after adsorption process. The $\mathrm{H}-\mathrm{S}$ bond lengths in isolated $\mathrm{H}_{2} \mathrm{~S}(1.35 \AA)$ are extended to 1.36 and $1.95 \AA$, indicating that the molecule is fully dissociated during the adsorption process into the chemisorbed $\mathrm{H}$ and separated HS species. While the first HS bond dissociates, the second one does not. Therefore, dissociation of adsorbed $\mathrm{H}_{2} \mathrm{~S}$ to adsorbed $\mathrm{H}$ and $\mathrm{HS}$ occurs on the surface of $\mathrm{ZnO}$ according to the following process:

$$
\mathrm{H}_{2} \mathrm{~S}_{(\text {ada })} \rightarrow \mathrm{HS}+\mathrm{H}_{(\text {ads })}
$$

The $\mathrm{H}$ atom of the molecule forms a covalent bond with the $\mathrm{O}$ atom of the $\mathrm{ZnO}$ with a bond length of $1.75 \AA$. The H-S-H bond angle of the isolated $\mathrm{H}_{2} \mathrm{~S}$ increases from $91.29^{\circ}$ to $92.63^{\circ}$ after complexation with $\mathrm{ZnO}$-graphene sensor. The $\mathrm{Zn}-\mathrm{C}_{1}, \mathrm{Zn}-\mathrm{C}_{2}$, and $\mathrm{C}_{1}-\mathrm{C}_{2}$ bond lengths are 2.24, 2.13, and $1.45 \AA$, respectively. Although $\mathrm{H}_{2} \mathrm{~S}$ and $\mathrm{H}_{2} \mathrm{O}$ are quite similar molecules, the strength of the HS compared to $\mathrm{HO}$ bonds is significantly different. The much higher preference of $\mathrm{H}_{2} \mathrm{~S}$ 
to dissociate in comparison with $\mathrm{H}_{2} \mathrm{O}$ can be related to the different acidity of the two molecules and the much lower pKa value of $\mathrm{H}_{2} \mathrm{~S}$ [87]. The adsorption energy of $\mathrm{H}_{2} \mathrm{~S}$ on the $\mathrm{ZnO}$-graphene compound is $-1.01 \mathrm{eV}$ which is accompanied by a charge transfer of $0.121 \mathrm{e}$ from the molecule to the sensor. $\mathrm{H}_{2} \mathrm{~S}$ prefers to dissociatively adsorb on the $\mathrm{ZnO}(10 \overline{10})$ surface with an adsorption energy of $-1.36 \mathrm{eV}$ [88]. Moreover, the calculated $E_{a d}$ of $\mathrm{H}_{2} \mathrm{~S}$ on the $\mathrm{ZnO}$-graphene compound is higher than the values reported for its adsorption on the pristine graphene $(-0.11 \mathrm{eV})$ [89], pristine $\mathrm{ZnO}$ (0001) $(-0.91 \mathrm{eV})$ [90], and pristine hexagonal monolayer $\mathrm{ZnO}(-0.54 \mathrm{eV})$ [91] surfaces, proposing the great capability of the $\mathrm{ZnO}$-graphene hybrid for $\mathrm{H}_{2} \mathrm{~S}$ dissociation. The experimental reported data confirm our DFT findings. Song et al. experimentally shown that the dispersion of $\mathrm{ZnO}$ nanoparticle on the reduced graphene sheet promotes the $\mathrm{H}_{2} \mathrm{~S}$ adsorption capacities [92]. Moreover, Cuong et al. demonstrated that a sensor based on vertically aligned $\mathrm{ZnO}$ nanorods on a graphene film effectively detects 2 ppm of $\mathrm{H}_{2} \mathrm{~S}$ in oxygen at room temperature [93].

In order to better understand the binding strength of the gas molecules adsorption, the electronic total charges density of $\mathrm{ZnO}$-graphene is obtained and compared with those calculated for gas molecules-ZnO-graphene complexes, as shown in Figure 4. An orbital overlap can be observed between $\mathrm{ZnO}$ and the graphene sheet, confirming this theory that $\mathrm{ZnO}$ is chemically adsorbed on the graphene sheet. For $\mathrm{NO}$ and $\mathrm{NO}_{2}$, an orbital overlap can be seen between the gas molecules and the $\mathrm{ZnO}$, revealing the occurrence of the strong chemisorption. This strong orbital mixing is attributed to the large charge transfer to the sensor. The weak interactions of the $\mathrm{NH}_{3}$ and $\mathrm{H}_{2} \mathrm{O}$ with the $\mathrm{ZnO}$-graphene sensor can be verified by studying the electronic total charge densities of the molecules-sensor compound. It can be seen that there is no orbital overlap between the molecules previously stated and the sensor. In consistent with our obtained results, while the electron density of the $\mathrm{H}$ atom of the $\mathrm{H}_{2} \mathrm{~S}$ is bonded with the $\mathrm{O}$ atom of the $\mathrm{ZnO}$, the $\mathrm{HS}$ part of the gas molecule has no overlap with the sensor, confirming the full dissociation of the hydrogen sulfide molecule through the adsorption process.

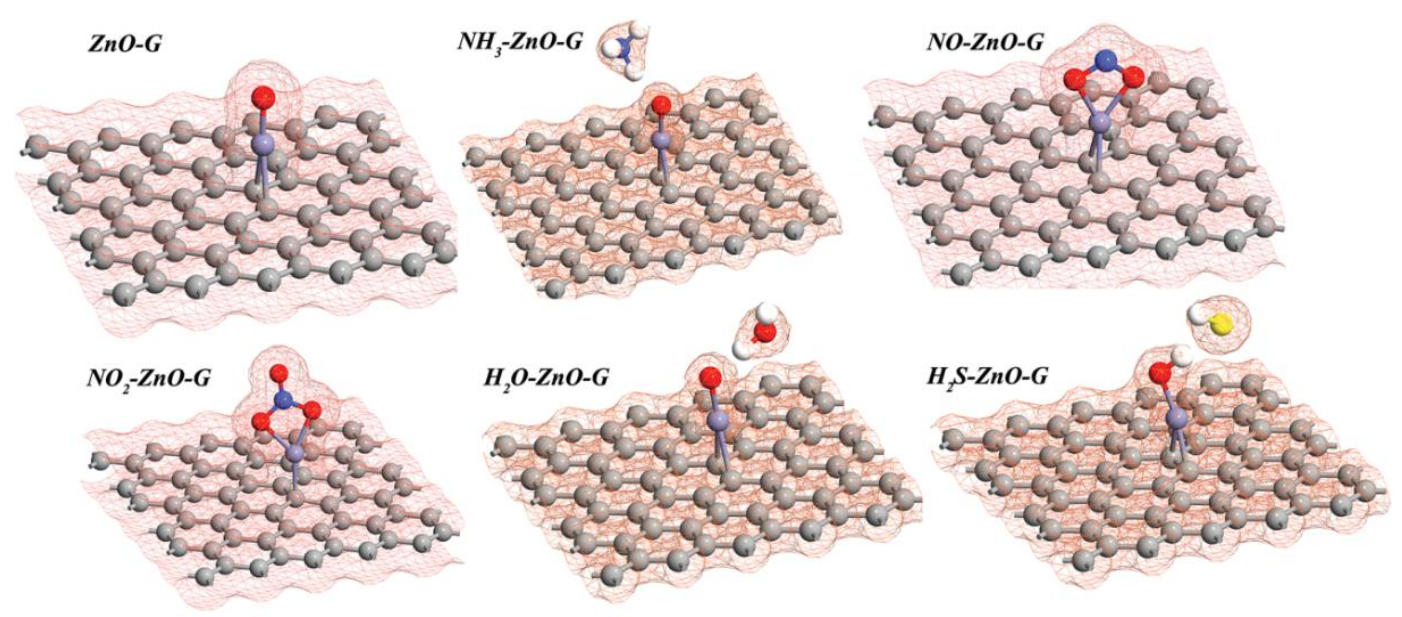

Figure 4. The electronic total charge densities of the $\mathrm{ZnO}$-graphene sensor before and after complexation with $\mathrm{NH}_{3}, \mathrm{NO}, \mathrm{NO}_{2}, \mathrm{H}_{2} \mathrm{O}$, and $\mathrm{H}_{2} \mathrm{~S}$. The gray, purple, red, blue, yellow, and white balls represent $\mathrm{C}, \mathrm{Zn}, \mathrm{O}, \mathrm{N}, \mathrm{S}$, and $\mathrm{H}$ atoms, respectively.

It is worth mentioning that the electronic properties of the sensor undergo significant changes owing to orbital mixing and the charge transfer between the molecule and the sensor, which is favorable for gas sensing applications. To explore the effect of gas molecules adsorption on the electronic properties of the sensor, the band structure of the $\mathrm{ZnO}$-graphene sensor before and after exposure are calculated, and plotted in Figure 5. As discussed earlier, the $\mathrm{ZnO}$-graphene sensor shows n-type behavior due to the transferred electrons from the $\mathrm{ZnO}$ to graphene. This causes a downward shift of the graphene's Dirac point to the negative energies and opens a gap of $26 \mathrm{meV}$ 
between conduction (band $c$ ) and valence (band $v$ ) bands of the graphene, which are highlighted with green color in Figure 5. When the $\mathrm{ZnO}$-graphene sensor is exposed to the gas molecules, different amount of electrons are transferred from the molecules to the sensor which dropped more the K-point of the hybrid structure. The band structure of the sensor changed a little upon adsorption of $\mathrm{NH}_{3}$ and $\mathrm{H}_{2} \mathrm{O}$. However, the variation in the electronic properties of the sensor after $\mathrm{NH}_{3}$ adsorption (mostly in the $c$ band) is more pronounced compared to that upon $\mathrm{H}_{2} \mathrm{O}$ adsorption. The gap of the hybrid sensor is slightly increased to 33 and $30 \mathrm{meV}$ after $\mathrm{NH}_{3}$ and $\mathrm{H}_{2} \mathrm{O}$ adsorption. These small changes agree well with the small number of electrons transferred from $\mathrm{NH}_{3}(+0.056 e)$ and $\mathrm{H}_{2} \mathrm{O}$ $(+0.031 e)$ to the sensor. Upon exposure to $\mathrm{NO}$ and $\mathrm{NO}_{2}$, the $c$ and $v$ bands are shifted even more to the negative energies, implying that the sensor's n-type behavior is enhanced. The reason for this phenomena is the large electron transfer after adsorption of $\mathrm{NO}(+0.155 e)$ and $\mathrm{NO}_{2}(+0.141 e)$ onto the sensor. Additionally, the gap between the bands are widened to 68 and $171 \mathrm{meV}$ after the interaction of the sensor with $\mathrm{NO}$ and $\mathrm{NO}_{2}$ gas molecules, correspondingly. Finally, the band structure of the sensor undergoes substantial alterations after interacting with the $\mathrm{H}_{2} \mathrm{~S}$ gas molecule. The energy range of band $c$ is extended towards the positive electron energies, while the energy range of band $v$ is shrunken. Moreover, the gap between bands $c$ and $v$ at $\mathrm{K}$-point increases to $66 \mathrm{meV}$, while its location is moved down. These changes can be attributed to the dissociation of the $\mathrm{H}_{2} \mathrm{~S}$ after interacting with the sensor inducing an electron transfer of $+0.121 e$ from the molecule to the sensor.
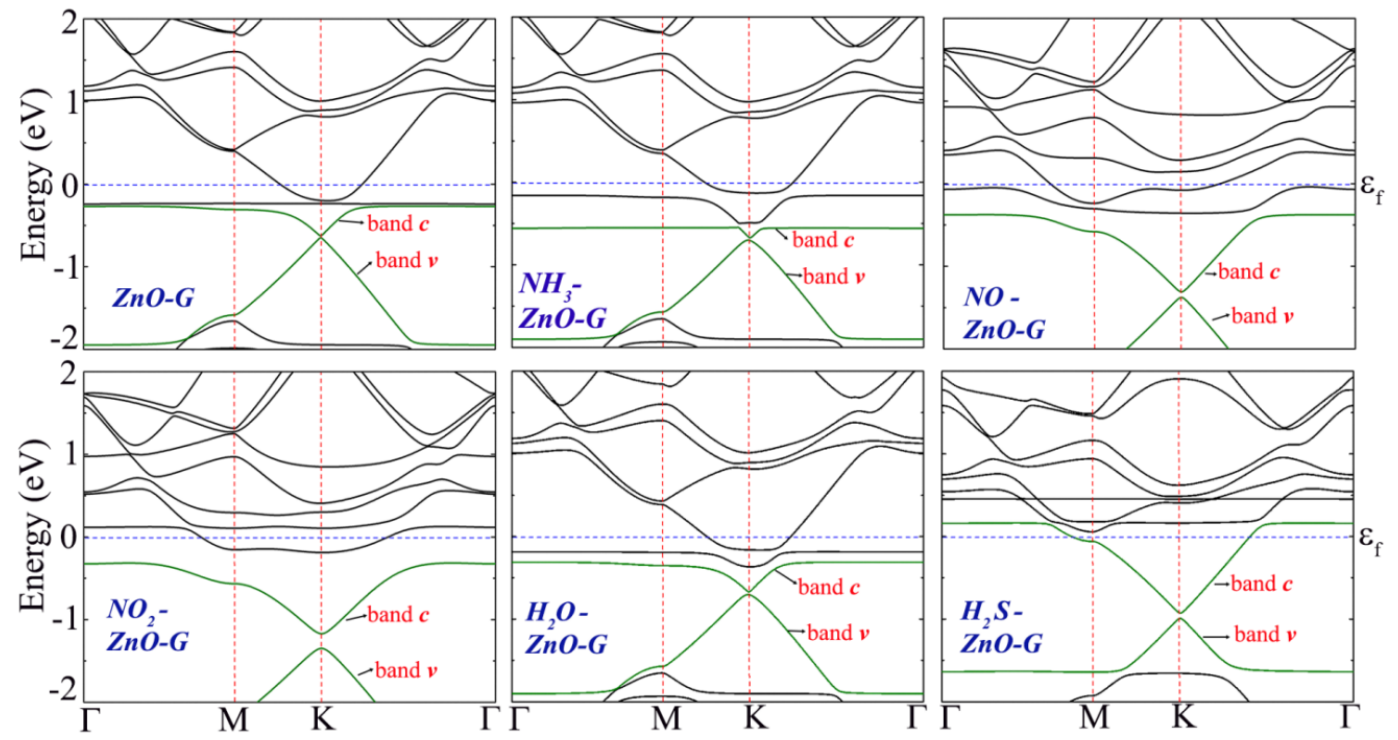

Figure 5. The electronic band structures of the $\mathrm{ZnO}$-graphene sensor before and after adsorption of $\mathrm{NH}_{3}, \mathrm{NO}, \mathrm{NO}_{2}, \mathrm{H}_{2} \mathrm{O}$, and $\mathrm{H}_{2} \mathrm{~S}$. Valance and conduction bands are highlighted in green. The Fermi levels, indicated in blue dashed lines, have been set to $0 \mathrm{eV}$.

The charge transfer caused by the gas molecules adsorption brings about alterations in the conductance of the sensor which is a key element for assessing the performance of the substrate material. To learn about the impacts of the gas molecule adsorption on the transport properties of the sensor, we calculate the quantum conductances of the two-point probe sensor (see Figure 1) with and without the gas molecules' adsorption, as plotted in Figure 6. This also helps us understand better the ability of the sensor to detect the aforementioned gas molecules. As seen in Figure 6, pristine graphene shows semi-metallic behavior with zero band gap and zero conductance at the Fermi level. The $\mathrm{ZnO}$ adsorption significantly stimulates the transport property of graphene. The electronic states of the $\mathrm{ZnO}$-graphene hybrid at the Fermi level are noticeably increased due to the electrons transfer, resulting in an enhancement to the conductance of the system. The quantum conductance of the sensor is found to be $0.342 e^{2} / h$ at the Fermi level. In addition, the metallic $\mathrm{ZnO}-$ graphene compound shows 
a peak at electron energy of $-0.24 \mathrm{eV}$. The conductance of the compound drops to zero at electron energy of $-0.64 \mathrm{eV}$, confirming the existence of a gap between $c$ and $v$ bands in its band structure, as discussed before. The conductances of the $\mathrm{ZnO}$-graphene sensor before and after adsorption of $\mathrm{NH}_{3}$ and $\mathrm{H}_{2} \mathrm{O}$ molecules vary very little, suggesting low level of sensitivity to these molecules. However, the alterations of the quantum conductances are more prominent for the other complexes. Once NO $\left(\mathrm{NO}_{2}\right)$ is absorbed on the sensor, the quantum conductance of the sensor increases from 0.34 to 0.97 (0.81) $2 e^{2} / h$. Furthermore, the sensor shows no conductivity for the electron energy range of -1.28 to $-1.11 \mathrm{eV}$ after $\mathrm{NO}_{2}$ adsorption and -1.40 to $-1.33 \mathrm{eV}$ after interaction with $\mathrm{NO}$, which concurs well with our previous findings for their corresponding band structures. The observable conductance changes, high adsorption energy, and large charge transfer indicate the promising applications of the $\mathrm{ZnO}$-graphene as a sensitive chemical sensor for $\mathrm{NO}$ and $\mathrm{NO}_{2}$ detection. One can also see that the interactions of the $\mathrm{H}_{2} \mathrm{~S}$ with the sensor increase the quantum conductance to $0.592 e^{2} / h$. The quantum conductance of the sensor after adsorption of $\mathrm{H}_{2} \mathrm{~S}$ is zero in the electron energy between -1.02 to $-0.95 \mathrm{eV}$, indicating a shift of $0.36 \mathrm{eV}$ to the negative electron energies in comparison with that of an unexposed sensor. Consequently, the $\mathrm{ZnO}$-graphene sensor might be a potential catalyst for dissociation of the $\mathrm{H}_{2} \mathrm{~S}$ gas molecule. These results are in good agreement with reported experimental results, showing that the ability of graphene-based sensors to detect $\mathrm{NH}_{3}$ [55], $\mathrm{NO}$ [55], $\mathrm{NO}_{2}$ [67,94], and $\mathrm{H}_{2} \mathrm{~S}[57,95]$ are significantly enhanced after adsorption of $\mathrm{ZnO}$.

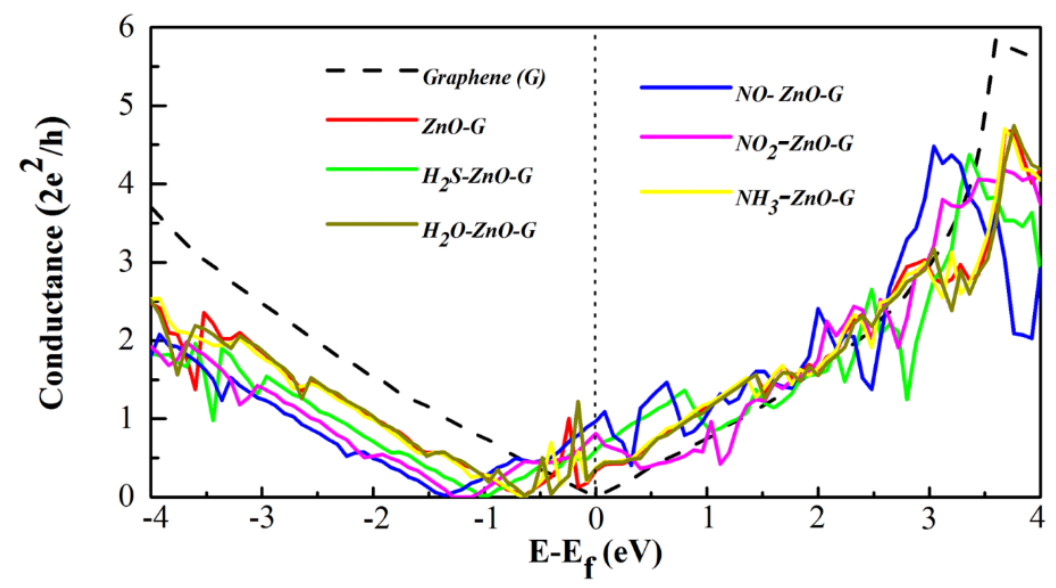

Figure 6. Quantum conductance of the $\mathrm{ZnO}-$ graphene sensor before and after complexation with $\mathrm{NH}_{3}$, $\mathrm{NO}, \mathrm{NO}_{2}, \mathrm{H}_{2} \mathrm{O}$, and $\mathrm{H}_{2} \mathrm{~S}$ as a function of electron energy.

The sensing capability of the $\mathrm{ZnO}$-graphene sensor to various gas molecules are also assessed by quantifying its sensitivity, which can be expressed as follows:

$$
S(\%)=\frac{\left|C-C_{0}\right|}{C_{0}}
$$

Here, $C$ and $C_{0}$ are the zero bias conductances for the nanosensor with and without the gas molecules, respectively. The results obtained are listed in Table 1. The sensitivities of $\mathrm{NH}_{3}, \mathrm{NO}$, $\mathrm{NO}_{2}, \mathrm{H}_{2} \mathrm{O}$, and $\mathrm{H}_{2} \mathrm{~S}$ gas molecules on the sensor are calculated to be $11.8 \%, 188.2 \%, 141.1 \%, 6.4 \%$, and $76.47 \%$, respectively. The sensitivities of the sensor to $\mathrm{NO}, \mathrm{NO}_{2}$, and $\mathrm{H}_{2} \mathrm{~S}$ are much larger than its sensitivity to $\mathrm{H}_{2} \mathrm{O}$, showing superior sensitivity and selectivity toward those gas molecules even in the presence of water vapor. Another important factor for evaluating the performance of a gas sensor is the recovery time $(\tau)$, which can be described using conventional transition state theory as follows:

$$
\tau \propto \exp \left(-E_{a d} / k_{B} T\right)
$$


A small adsorption energy can result in a fast desorption process of the gases from the sensor. The recovery time is found to follow an ascending order of $\mathrm{H}_{2} \mathrm{O}<\mathrm{NH}_{3}<\mathrm{H}_{2} \mathrm{~S}<\mathrm{NO}_{2}<\mathrm{NO}$. The sensor shows a low level of sensitivity to the $\mathrm{NH}_{3}$ in spite of the short recovery time. Interestingly, the sensor shows promise to work under humid air as a result of its low sensitivity and quick recovery time to water molecules. Since the chemisorption of $\mathrm{NO}_{2}$ and $\mathrm{NO}$ is accompanied with high adsorption energies, much longer time is necessary to completely desorb the gas molecules. Hence, the $\mathrm{ZnO}$-graphene sensor can be utilized as a disposable molecule sensor for specific $\mathrm{NO}$ and $\mathrm{NO}_{2}$ detection. Lastly, the moderate adsorption energy for $\mathrm{H}_{2} \mathrm{~S}$ suggests that it is possible to desorb it from the sensor by heating at room temperature, revealing a great potential of the $\mathrm{ZnO}$-graphene hybrid to be used as $\mathrm{H}_{2} \mathrm{~S}$ catalyst.

\section{Conclusions}

We performed detailed first-principles computational analysis on the geometric and electronic transport properties of the $\mathrm{ZnO}$-graphene hybrid gas sensor upon interaction with $\mathrm{NH}_{3}, \mathrm{NO}, \mathrm{NO}_{2}$, $\mathrm{H}_{2} \mathrm{O}$, and $\mathrm{H}_{2} \mathrm{~S}$ gas molecules. It was found that $\mathrm{NH}_{3}$ and $\mathrm{H}_{2} \mathrm{O}$ are adsorbed on the sensor with weak hydrogen bonds. These weak interactions caused small variations in the electronic transport properties of the sensor that can be attributed to the small charge transfer from $\mathrm{NH}_{3}$ and $\mathrm{H}_{2} \mathrm{O}$ to the sensor. However, the $\mathrm{NO}$ and $\mathrm{NO}_{2}$ are chemisorbed with a high adsorption energy and large charge transfer, resulting in significant alterations in the conductance of the $\mathrm{ZnO}$-graphene hybrid gas sensor. Interestingly, the $\mathrm{H}_{2} \mathrm{~S}$ gas molecule is chemisorbed through a dissociative mechanism which is accompanied by a large charge transfer from the molecule to the sensor, leaving noticeable changes in the electronic transport properties of the sensor. Consequently, $\mathrm{ZnO}-$ graphene is a potential material for $\mathrm{NO}$ and $\mathrm{NO}_{2}$ detection and is a propitious catalyst for $\mathrm{H}_{2} \mathrm{~S}$ dissociation.

Author Contributions: S.B. and C.W. conceived the original idea; I.T., S.M.A. and A.R.B. performed the simulations; I.T. and S.M.A. analyzed the results; I.T. and S.M.A. wrote the paper.

Funding: This research received no external funding.

Conflicts of Interest: The authors declare no conflict of interest.

\section{References}

1. Novoselov, K.S.; Geim, A.K.; Morozov, S.V.; Jiang, D.; Zhang, Y.; Dubonos, S.V.; Grigorieva, I.V.; Firsov, A.A. Electric field effect in atomically thin carbon films. Science 2004, 306, 666-669. [CrossRef] [PubMed]

2. Novoselov, K.S.; Geim, A.K.; Morozov, S.; Jiang, D.; Katsnelson, M.; Grigorieva, I.; Dubonos, S.; Firsov, A. Two-dimensional gas of massless Dirac fermions in graphene. Nature 2005, 438, 197-200. [CrossRef] [PubMed]

3. Schedin, F.; Geim, A.; Morozov, S.; Hill, E.; Blake, P.; Katsnelson, M.; Novoselov, K. Detection of individual gas molecules adsorbed on graphene. Nat. Mater. 2007, 6, 652-655. [CrossRef] [PubMed]

4. Basu, S.; Bhattacharyya, P. Recent developments on graphene and graphene oxide based solid state gas sensors. Sens. Actuators B Chem. 2012, 173, 1-21. [CrossRef]

5. He, Q.; Wu, S.; Yin, Z.; Zhang, H. Graphene-based electronic sensors. Chem. Sci. 2012, 3, $1764-1772$. [CrossRef]

6. Leenaerts, O.; Partoens, B.; Peeters, F. Adsorption of $\mathrm{H}_{2} \mathrm{O}, \mathrm{NH}_{3}, \mathrm{CO}, \mathrm{NO}_{2}$, and $\mathrm{NO}$ on graphene: A first-principles study. Phys. Rev. B 2008, 77, 125416. [CrossRef]

7. Zhang, Y.-H.; Chen, Y.-B.; Zhou, K.-G.; Liu, C.-H.; Zeng, J.; Zhang, H.-L.; Peng, Y. Improving gas sensing properties of graphene by introducing dopants and defects: A first-principles study. Nanotechnology 2009, 20, 185504. [CrossRef] [PubMed]

8. Dai, J.; Yuan, J.; Giannozzi, P. Gas adsorption on graphene doped with B, N, Al, and S: A theoretical study. Appl. Phys. Lett. 2009, 95, 232105. [CrossRef]

9. Robinson, J.T.; Perkins, F.K.; Snow, E.S.; Wei, Z.; Sheehan, P.E. Reduced graphene oxide molecular sensors. Nano Lett. 2008, 8, 3137-3140. [CrossRef] [PubMed] 
10. Lu, G.; Ocola, L.E.; Chen, J. Reduced graphene oxide for room-temperature gas sensors. Nanotechnology 2009, 20, 445502. [CrossRef] [PubMed]

11. Dai, J.; Yuan, J. Adsorption of molecular oxygen on doped graphene: Atomic, electronic, and magnetic properties. Phys. Rev. B 2010, 81, 165414. [CrossRef]

12. Nasehnia, F.; Seifi, M. Adsorption of molecular oxygen on VIIIB transition metal-doped graphene: A DFT study. Mod. Phys. Lett. B 2014, 28, 1450237. [CrossRef]

13. Borisova, D.; Antonov, V.; Proykova, A. Hydrogen sulfide adsorption on a defective graphene. Int. J. Quantum Chem. 2013, 113, 786-791. [CrossRef]

14. Liu, W.; Liu, Y.; Wang, R.; Hao, L.; Song, D.; Li, Z. DFT study of hydrogen adsorption on Eu-decorated single-and double-sided graphene. Phys. Status Solidi B 2014, 251, 229-234. [CrossRef]

15. Fowler, J.D.; Allen, M.J.; Tung, V.C.; Yang, Y.; Kaner, R.B.; Weiller, B.H. Practical chemical sensors from chemically derived graphene. ACS Nano 2009, 3, 301-306. [CrossRef] [PubMed]

16. Ko, G.; Kim, H.-Y.; Ahn, J.; Park, Y.-M.; Lee, K.-Y.; Kim, J. Graphene-based nitrogen dioxide gas sensors. Curr. Appl. Phys. 2010, 10, 1002-1004. [CrossRef]

17. Chen, G.; Paronyan, T.M.; Harutyunyan, A.R. Sub-ppt gas detection with pristine graphene. Appl. Phys. Lett. 2012, 101, 053119. [CrossRef]

18. Some, S.; Xu, Y.; Kim, Y.; Yoon, Y.; Qin, H.; Kulkarni, A.; Kim, T.; Lee, H. Highly sensitive and selective gas sensor using hydrophilic and hydrophobic graphenes. Sci. Rep. 2013, 3, 1868. [CrossRef] [PubMed]

19. Fattah, A.; Khatami, S. Selective $\mathrm{H}_{2} \mathrm{~S}$ Gas Sensing with a Graphene/n-Si Schottky Diode. IEEE Sens. J. 2014, 14, 4104-4108. [CrossRef]

20. Prezioso, S.; Perrozzi, F.; Giancaterini, L.; Cantalini, C.; Treossi, E.; Palermo, V.; Nardone, M.; Santucci, S.; Ottaviano, L. Graphene oxide as a practical solution to high sensitivity gas sensing. J. Phys. Chem. C 2013, 117, 10683-10690. [CrossRef]

21. Hafiz, S.M.; Ritikos, R.; Whitcher, T.J.; Razib, N.M.; Bien, D.C.S.; Chanlek, N.; Nakajima, H.; Saisopa, T.; Songsiriritthigul, P.; Huang, N.M. A practical carbon dioxide gas sensor using room-temperature hydrogen plasma reduced graphene oxide. Sens. Actuators B Chem. 2014, 193, 692-700. [CrossRef]

22. Hu, N.; Wang, Y.; Chai, J.; Gao, R.; Yang, Z.; Kong, E.S.-W.; Zhang, Y. Gas sensor based on p-phenylenediamine reduced graphene oxide. Sens. Actuators B Chem. 2012, 163, 107-114. [CrossRef]

23. Kwon, Y.J.; Cho, H.Y.; Na, H.G.; Lee, B.C.; Kim, S.S.; Kim, H.W. Improvement of gas sensing behavior in reduced graphene oxides by electron-beam irradiation. Sens. Actuators B Chem. 2014, 203, 143-149. [CrossRef]

24. Topsakal, M.; Aktürk, E.; Sevinçli, H.; Ciraci, S. First-principles approach to monitoring the band gap and magnetic state of a graphene nanoribbon via its vacancies. Phys. Rev. B 2008, 78, 235435. [CrossRef]

25. Lu, P.; Zhang, Z.; Guo, W. Electronic and magnetic properties of zigzag edge graphene nanoribbons with Stone-Wales defects. Phys. Lett. A 2009, 373, 3354-3358. [CrossRef]

26. Lopez-Bezanilla, A.; Zhou, W.; Idrobo, J.-C. Electronic and Quantum Transport Properties of Atomically Identified Si Point Defects in Graphene. J. Phys. Chem. Lett. 2014, 5, 1711-1718. [CrossRef] [PubMed]

27. Aghaei, S.M.; Monshi, M.M.; Torres, I.; Calizo, I. Edge functionalization and doping effects on the stability, electronic and magnetic properties of silicene nanoribbons. RSC Adv. 2016, 6, 17046-17058. [CrossRef]

28. Rad, A.S. First principles study of Al-doped graphene as nanostructure adsorbent for $\mathrm{NO}_{2}$ and $\mathrm{N}_{2} \mathrm{O}$ : DFT calculations. Appl. Surf. Sci. 2015, 357, 1217-1224. [CrossRef]

29. Tit, N.; Said, K.; Mahmoud, N.M.; Kouser, S.; Yamani, Z.H. Ab-initio investigation of adsorption of CO and $\mathrm{CO}_{2}$ molecules on graphene: Role of intrinsic defects on gas sensing. Appl. Surf. Sci. 2017, 394, 219-230. [CrossRef]

30. Ma, L.; Zhang, J.-M.; Xu, K.-W.; Ji, V. A first-principles study on gas sensing properties of graphene and Pd-doped graphene. Appl. Surf. Sci. 2015, 343, 121-127. [CrossRef]

31. Gupta, S.; Sabarou, H.; Zhong, Y.; Singh, P. Phase evolution and electrochemical performance of iron doped lanthanum strontium chromite in oxidizing and reducing atmosphere. Int. J. Hydrogen Energy 2017, 42, 6262-6271. [CrossRef]

32. Chawla, N.; Chamaani, A.; Safa, M.; El-Zahab, B. Palladium-Filled Carbon Nanotubes Cathode for Improved Electrolyte Stability and Cyclability Performance of $\mathrm{Li}_{-} \mathrm{O}_{2}$ Batteries. J. Electrochem. Soc. 2017, 164, A6303-A6307. [CrossRef] 
33. Basu, S.; Hazra, S.K. Graphene-Noble Metal Nano-Composites and Applications for Hydrogen Sensors. C 2017, 3, 29. [CrossRef]

34. Li, H.; Yin, Z.; He, Q.; Li, H.; Huang, X.; Lu, G.; Fam, D.W.H.; Tok, A.I.Y.; Zhang, Q.; Zhang, H. Fabrication of single-and multilayer $\mathrm{MoS}_{2}$ film-based field-effect transistors for sensing $\mathrm{NO}$ at room temperature. Small 2012, 8, 63-67. [CrossRef] [PubMed]

35. He, Q.; Zeng, Z.; Yin, Z.; Li, H.; Wu, S.; Huang, X.; Zhang, H. Fabrication of Flexible $\mathrm{MoS}_{2}$ Thin-Film Transistor Arrays for Practical Gas-Sensing Applications. Small 2012, 8, 2994-2999. [CrossRef] [PubMed]

36. Donarelli, M.; Prezioso, S.; Perrozzi, F.; Bisti, F.; Nardone, M.; Giancaterini, L.; Cantalini, C.; Ottaviano, L. Response to $\mathrm{NO}_{2}$ and other gases of resistive chemically exfoliated $\mathrm{MoS}_{2}$-based gas sensors. Sens. Actuators B Chem. 2015, 207, 602-613. [CrossRef]

37. Kou, L.; Frauenheim, T.; Chen, C. Phosphorene as a superior gas sensor: Selective adsorption and distinct IV response. J. Phys. Chem. Lett. 2014, 5, 2675-2681. [CrossRef] [PubMed]

38. Abbas, A.N.; Liu, B.; Chen, L.; Ma, Y.; Cong, S.; Aroonyadet, N.; Köpf, M.; Nilges, T.; Zhou, C. Black phosphorus gas sensors. ACS Nano 2015, 9, 5618-5624. [CrossRef] [PubMed]

39. Mahabal, M.S.; Deshpande, M.D.; Hussain, T.; Ahuja, R. Sensing Characteristics of a Graphene-like Boron Carbide Monolayer towards Selected Toxic Gases. Chemphyschem 2015, 16, 3511-3517. [CrossRef] [PubMed]

40. Aghaei, S.M.; Monshi, M.; Torres, I.; Zeidi, S.; Calizo, I. DFT study of adsorption behavior of NO, CO, NO and $\mathrm{NH}_{3}$ molecules on graphene-like $\mathrm{BC}_{3}$ : A search for highly sensitive molecular sensor. Appl. Surf. Sci. 2018, 427, 326-333. [CrossRef]

41. Huo, N.; Yang, S.; Wei, Z.; Li, S.-S.; Xia, J.-B.; Li, J. Photoresponsive and gas sensing field-effect transistors based on multilayer $\mathrm{WS}_{2}$ nanoflakes. Sci. Rep. 2014, 4, 5209. [CrossRef] [PubMed]

42. O’Brien, M.; Lee, K.; Morrish, R.; Berner, N.C.; McEvoy, N.; Wolden, C.A.; Duesberg, G.S. Plasma assisted synthesis of $\mathrm{WS}_{2}$ for gas sensing applications. Chem. Phys. Lett. 2014, 615, 6-10. [CrossRef]

43. Hu, W.; Xia, N.; Wu, X.; Li, Z.; Yang, J. Silicene as a highly sensitive molecule sensor for $\mathrm{NH}_{3}, \mathrm{NO}$ and $\mathrm{NO}_{2}$. Phys. Chem. Chem. Phys. 2014, 16, 6957-6962. [CrossRef] [PubMed]

44. Chandiramouli, R.; Srivastava, A.; Nagarajan, V. NO adsorption studies on silicene nanosheet: DFT investigation. Appl. Surf. Sci. 2015, 351, 662-672. [CrossRef]

45. Aghaei, S.M.; Monshi, M.M.; Calizo, I. A theoretical study of gas adsorption on silicene nanoribbons and its application in a highly sensitive molecule sensor. RSC Adv. 2016, 6, 94417-94428. [CrossRef]

46. Monshi, M.M.; Aghaei, S.M.; Calizo, I. Doping and defect-induced germanene: A superior media for sensing $\mathrm{H}_{2} \mathrm{~S}, \mathrm{SO}_{2}$, and $\mathrm{CO}_{2}$ gas molecules. Surf. Sci. 2017, 665, 96-102. [CrossRef]

47. Rai, P.; Kwak, W.-K.; Yu, Y.-T. Solvothermal synthesis of ZnO nanostructures and their morphology-dependent gas-sensing properties. ACS Appl. Mater. Interfaces 2013, 5, 3026-3032. [CrossRef] [PubMed]

48. Maeng, S.; Kim, S.-W.; Lee, D.-H.; Moon, S.-E.; Kim, K.-C.; Maiti, A. $\mathrm{SnO}_{2}$ nanoslab as $\mathrm{NO}_{2}$ sensor: Identification of the $\mathrm{NO}_{2}$ sensing mechanism on a $\mathrm{SnO}_{2}$ surface. ACS Appl. Mater. Interfaces 2013, 6, 357-363. [CrossRef] [PubMed]

49. Chen, M.; Wang, Z.; Han, D.; Gu, F.; Guo, G. Porous ZnO polygonal nanoflakes: Synthesis, use in high-sensitivity $\mathrm{NO}_{2}$ gas sensor, and proposed mechanism of gas sensing. J. Phys. Chem. C 2011, 115, 12763-12773. [CrossRef]

50. Rossinyol, E.; Prim, A.; Pellicer, E.; Arbiol, J.; Hernández-Ramírez, F.; Peiró, F.; Cornet, A.; Morante, J.R.; Solovyov, L.A.; Tian, B. Synthesis and Characterization of Chromium-Doped Mesoporous Tungsten Oxide for Gas Sensing Applications. Adv. Funct. Mater. 2007, 17, 1801-1806. [CrossRef]

51. Epifani, M.; Díaz, R.; Arbiol, J.; Comini, E.; Sergent, N.; Pagnier, T.; Siciliano, P.; Faglia, G.; Morante, J.R. Nanocrystalline Metal Oxides from the Injection of Metal Oxide Sols in Coordinating Solutions: Synthesis, Characterization, Thermal Stabilization, Device Processing, and Gas-Sensing Properties. Adv. Funct. Mater. 2006, 16, 1488-1498. [CrossRef]

52. Hazra, S.K.; Basu, S. Graphene-Oxide Nano Composites for Chemical Sensor Applications. C 2016, 2, 12. [CrossRef]

53. Lin, Q.; Li, Y.; Yang, M. Tin oxide/graphene composite fabricated via a hydrothermal method for gas sensors working at room temperature. Sens. Actuators B Chem. 2012, 173, 139-147. [CrossRef]

54. Zhang, H.; Feng, J.; Fei, T.; Liu, S.; Zhang, T. $\mathrm{SnO}_{2}$ nanoparticles-reduced graphene oxide nanocomposites for $\mathrm{NO}_{2}$ sensing at low operating temperature. Sens. Actuators B Chem. 2014, 190, 472-478. [CrossRef] 
55. Singh, G.; Choudhary, A.; Haranath, D.; Joshi, A.G.; Singh, N.; Singh, S.; Pasricha, R. ZnO decorated luminescent graphene as a potential gas sensor at room temperature. Carbon 2012, 50, 385-394. [CrossRef]

56. Jammula, R.K.; Srikanth, V.V.; Hazra, B.K.; Srinath, S. ZnO nanoparticles' decorated reduced-graphene oxide: Easy synthesis, unique polarization behavior, and ionic conductivity. Mater. Des. 2016, 110, 311-316. [CrossRef]

57. Lonkar, S.P.; Pillai, V.; Abdala, A.; Mittal, V. In situ formed graphene/ZnO nanostructured composites for low temperature hydrogen sulfide removal from natural gas. RSC Adv. 2016, 6, 81142-81150. [CrossRef]

58. Zhou, L.; Shen, F.; Tian, X.; Wang, D.; Zhang, T.; Chen, W. Stable $\mathrm{Cu}_{2} \mathrm{O}$ nanocrystals grown on functionalized graphene sheets and room temperature $\mathrm{H}_{2} \mathrm{~S}$ gas sensing with ultrahigh sensitivity. Nanoscale 2013, 5, 1564-1569. [CrossRef] [PubMed]

59. Mohammadi-Manesh, E.; Vaezzadeh, M.; Saeidi, M. Theoretical study on electronic structure, and electrical conductance at room temperature of $\mathrm{Cu}_{2} \mathrm{O}-\mathrm{GS}$ nanosensors and detection of $\mathrm{H}_{2} \mathrm{~S}$ gas. Comput. Mater. Sci. 2015, 97, 181-185. [CrossRef]

60. Fu, D.; Han, G.; Chang, Y.; Dong, J. The synthesis and properties of ZnO-graphene nano hybrid for photodegradation of organic pollutant in water. Mater. Chem. Phys. 2012, 132, 673-681. [CrossRef]

61. Shi, J.; Cheng, Z.; Gao, L.; Zhang, Y.; Xu, J.; Zhao, H. Facile synthesis of reduced graphene oxide/hexagonal $\mathrm{WO}_{3}$ nanosheets composites with enhanced $\mathrm{H}_{2} \mathrm{~S}$ sensing properties. Sens. Actuators B Chem. 2016, 230, 736-745. [CrossRef]

62. Chen, N.; Li, X.; Wang, X.; Yu, J.; Wang, J.; Tang, Z.; Akbar, S. Enhanced room temperature sensing of $\mathrm{Co}_{3} \mathrm{O}_{4}$-intercalated reduced graphene oxide based gas sensors. Sens. Actuators B Chem. 2013, 188, 902-908. [CrossRef]

63. Anand, K.; Singh, O.; Singh, M.P.; Kaur, J.; Singh, R.C. Hydrogen sensor based on graphene/ZnO nanocomposite. Sens. Actuators B Chem. 2014, 195, 409-415. [CrossRef]

64. Khadem, S.J.; Abdi, Y.; Darbari, S.; Ostovari, F. Investigating the effect of gas absorption on the electromechanical and electrochemical behavior of graphene/ZnO structure, suitable for highly selective and sensitive gas sensors. Curr. Appl. Phys. 2014, 14, 1498-1503. [CrossRef]

65. Monshi, M.M.; Aghaei, S.M.; Calizo, I. Band gap opening and optical absorption enhancement in graphene using ZnO nanocluster. Phys. Lett. A 2018, 382, 1171-1175. [CrossRef]

66. Zhang, D.; Yin, N.; Xia, B. Facile fabrication of ZnO nanocrystalline-modified graphene hybrid nanocomposite toward methane gas sensing application. J. Mater. Sci. Mater. Electron. 2015, 26, 5937-5945. [CrossRef]

67. Liu, S.; Yu, B.; Zhang, H.; Fei, T.; Zhang, T. Enhancing $\mathrm{NO}_{2}$ gas sensing performances at room temperature based on reduced graphene oxide-ZnO nanoparticles hybrids. Sens. Actuators B Chem. 2014, 202, 272-278. [CrossRef]

68. Xia, Y.; Wang, J.; Xu, J.-L.; Li, X.; Xie, D.; Xiang, L.; Komarneni, S. Confined formation of ultrathin ZnO nanorods/reduced graphene oxide mesoporous nanocomposites for high-performance room-temperature $\mathrm{NO}_{2}$ sensors. ACS Appl. Mater. Interfaces 2016, 8, 35454-35463. [CrossRef] [PubMed]

69. Huang, Q.; Zeng, D.; Li, H.; Xie, C. Room temperature formaldehyde sensors with enhanced performance, fast response and recovery based on zinc oxide quantum dots/graphene nanocomposites. Nanoscale 2012, 4, 5651-5658. [CrossRef] [PubMed]

70. Mu, H.; Zhang, Z.; Zhao, X.; Liu, F.; Wang, K.; Xie, H. High sensitive formaldehyde graphene gas sensor modified by atomic layer deposition zinc oxide films. Appl. Phys. Lett. 2014, 105, 033107. [CrossRef]

71. Zhang, D.; Liu, J.; Xia, B. Layer-by-layer self-assembly of zinc oxide/graphene oxide hybrid toward ultrasensitive humidity sensing. IEEE Electron Device Lett. 2016, 37, 916-919. [CrossRef]

72. Taylor, J.; Guo, H.; Wang, J. Ab initio modeling of quantum transport properties of molecular electronic devices. Phys. Rev. B 2001, 63, 245407. [CrossRef]

73. Brandbyge, M.; Mozos, J.-L.; Ordejón, P.; Taylor, J.; Stokbro, K. Density-functional method for nonequilibrium electron transport. Phys. Rev. B 2002, 65, 165401. [CrossRef]

74. Atomistix ToolKit (ATK), Version 2017.2, QuantumWise Simulator A/S. Available online: www. quantumwise.com (accessed on 9 August 2018).

75. Grimme, S. Semiempirical GGA-type density functional constructed with a long-range dispersion correction. J. Comput. Chem. 2006, 27, 1787-1799. [CrossRef] [PubMed] 
76. Grimme, S.; Mück-Lichtenfeld, C.; Antony, J. Noncovalent interactions between graphene sheets and in multishell (hyper) fullerenes. J. Phys. Chem. C 2007, 111, 11199-11207. [CrossRef]

77. Pyykkö, P.; Atsumi, M. Molecular Single-Bond Covalent Radii for Elements 1-118. Chem. A Eur. J. 2009, 15, 186-197. [CrossRef] [PubMed]

78. Zhang, Y.; Gao, B.; Xu, Z. Adsorption properties of polyvinyl-alcohol-grafted particles toward genistein driven by hydrogen-bond interaction. J. Phys. Chem. B 2013, 117, 5730-5736. [CrossRef] [PubMed]

79. Yuan, Q.; Zhao, Y.-P.; Li, L.; Wang, T. Ab initio study of ZnO-based gas-sensing mechanisms: Surface reconstruction and charge transfer. J. Phys. Chem. C 2009, 113, 6107-6113. [CrossRef]

80. Casarin, M.; Tondello, E.; Vittadini, A. A LCAO-LDF study of CO and NH3 chemisorption on ZnO (0001). Surf. Sci. 1994, 307, 1182-1187. [CrossRef]

81. An, W.; $\mathrm{Wu}, \mathrm{X}$; Zeng, X.C. Adsorption of $\mathrm{O}_{2}, \mathrm{H}_{2}, \mathrm{CO}, \mathrm{NH}_{3}$, and $\mathrm{NO}_{2}$ on $\mathrm{ZnO}$ nanotube: A density functional theory study. J. Phys. Chem. C 2008, 112, 5747-5755. [CrossRef]

82. Spencer, M.J.; Yarovsky, I. ZnO nanostructures for gas sensing: Interaction of $\mathrm{NO}_{2}, \mathrm{NO}, \mathrm{O}$, and $\mathrm{N}$ with the ZnO (1010) surface. J. Phys. Chem. C 2010, 114, 10881-10893. [CrossRef]

83. Breedon, M.; Spencer, M.; Yarovsky, I. Adsorption of $\mathrm{NO}_{2}$ on oxygen deficient $\mathrm{ZnO}$ (2110) for gas sensing applications: A DFT study. J. Phys. Chem. C 2010, 114, 16603-16610. [CrossRef]

84. Ma, J.; Michaelides, A.; Alfe, D.; Schimka, L.; Kresse, G.; Wang, E. Adsorption and diffusion of water on graphene from first principles. Phys. Rev. B 2011, 84, 033402. [CrossRef]

85. Ye, H.; Chen, G.; Niu, H.; Zhu, Y.; Shao, L.; Qiao, Z. Structures and mechanisms of water adsorption on ZnO (0001) and GaN (0001) surface. J. Phys. Chem. C 2013, 117, 15976-15983. [CrossRef]

86. Meyer, B.; Rabaa, H.; Marx, D. Water adsorption on $\mathrm{ZnO}$ (1010): From single molecules to partially dissociated monolayers. Phys. Chem. Chem. Phys. 2006, 8, 1513-1520. [CrossRef] [PubMed]

87. Goclon, J.; Meyer, B. The interaction of $\mathrm{H}_{2} \mathrm{~S}$ with the $\mathrm{ZnO}$ (1010) surface. Phys. Chem. Chem. Phys. 2013, 15, 8373-8382. [CrossRef] [PubMed]

88. Ling, L.; Zhang, R.; Han, P.; Wang, B. DFT study on the sulfurization mechanism during the desulfurization of $\mathrm{H}_{2} \mathrm{~S}$ on the $\mathrm{ZnO}$ desulfurizer. Fuel Process. Technol. 2013, 106, 222-230. [CrossRef]

89. Ganji, M.D.; Sharifi, N.; Ardjmand, M.; Ahangari, M.G. Pt-decorated graphene as superior media for $\mathrm{H}_{2} \mathrm{~S}$ adsorption: A first-principles study. Appl. Surf. Sci. 2012, 261, 697-704. [CrossRef]

90. Rodriguez, J.A.; Maiti, A. Adsorption and decomposition of $\mathrm{H}_{2} \mathrm{~S}$ on $\mathrm{MgO}(100), \mathrm{NiMgO}(100)$, and $\mathrm{ZnO}$ (0001) surfaces: A first-principles density functional study. J. Phys. Chem. B 2000, 104, 3630-3638. [CrossRef]

91. Zhang, Y.-H.; Yue, L.-J.; Gong, F.-L.; Li, F.; Zhang, H.-L.; Chen, J.-L. Highly enhanced $\mathrm{H}_{2} \mathrm{~S}$ gas sensing and magnetic performances of metal doped hexagonal ZnO monolayer. Vacuum 2017, 141, 109-115. [CrossRef]

92. Song, H.S.; Park, M.G.; Kwon, S.J.; Yi, K.B.; Croiset, E.; Chen, Z.; Nam, S.C. Hydrogen sulfide adsorption on nano-sized zinc oxide/reduced graphite oxide composite at ambient condition. Appl. Surf. Sci. 2013, 276, 646-652. [CrossRef]

93. Cuong, T.V.; Pham, V.H.; Chung, J.S.; Shin, E.W.; Yoo, D.H.; Hahn, S.H.; Huh, J.S.; Rue, G.H.; Kim, E.J.; Hur, S.H. Solution-processed ZnO-chemically converted graphene gas sensor. Mater. Lett. 2010, 64, 2479-2482. [CrossRef]

94. Liu, X.; Sun, J.; Zhang, X. Novel 3D graphene aerogel-ZnO composites as efficient detection for $\mathrm{NO}_{2}$ at room temperature. Sens. Actuators B Chem. 2015, 211, 220-226. [CrossRef]

95. Song, H.S.; Park, M.G.; Ahn, W.; Lim, S.N.; Yi, K.B.; Croiset, E.; Chen, Z.; Nam, S.C. Enhanced adsorption of hydrogen sulfide and regeneration ability on the composites of zinc oxide with reduced graphite oxide. Chem. Eng. J. 2014, 253, 264-273. [CrossRef]

(C) 2018 by the authors. Licensee MDPI, Basel, Switzerland. This article is an open access article distributed under the terms and conditions of the Creative Commons Attribution (CC BY) license (http://creativecommons.org/licenses/by/4.0/). 